\title{
EL CERCO DE NUMANCIA: EL CIERRE DEL DUERO
}

\author{
THE SIEGE OF NUMANCIA: THE CLOSING OF THE DUERO
}

POR

\author{
Fernando Morales Hernández*
}

\section{RESUMEN - ABSTRACT}

La relectura de los textos de Apiano posibilita una reinterpretación de los hallazgos y las teorías de Schulten. El profesor alemán identificó los fortines citados por Apiano para cerrar el río Duero en los lugares de Molino de Garrejo y Vega de Garray, llamándolos «castillos ribereños». Sin embargo, actualmente se acepta que ambas instalaciones son dos de los siete fuertes de la circunvalación.

Se propone aquí que los dos fortines construidos por Escipión para cerrar el Duero se encuentran en ambas orillas del mismo punto del río, unos 400 m aguas abajo del fuerte de Molino, allí donde Schulten creyó encontrar los restos del fallido propósito de Escipión por construir un puente, obra que, en mi opinión, ni siquiera intentó.

A new reading of Apiano's texts allows us a reinterpretation of the findings and theories of Schulten. The German professor identified the forts cited by Apiano to close the Duero River in the places of «Molino de Garrejo» and «Vega de Garray», calling them Uferkastell. However, at present is accepted that they are two of the seven forts of Numantia circumvallation.

Here it's proposed that the two forts built by Scipio to close the Duero River are at both banks of the river, one in front of the other, 400 meters downstream from the fort of Molino, where Schulten believed find the remains of the failed Scipio's purpose of building a bridge, work that in my own opinion, he didn't even attempt.

\section{Palabras Clave - Keywords}

Apiano; Schulten; Escipión Emiliano; asedio de Numancia; circunvalación escipiónica.

Appian; Schulten; Scipio Aemilianus; siege works of Numantia; Scipionic circumvallation.

Los trabajos de Schulten en torno a Numancia, desarrollados entre 1906 y 1908 principalmente, pusieron al descubierto un circuito formado por siete campamentos y dos castillos, y algunos tramos de la muralla del vallum, que el sabio alemán interpretó como correspondientes a la circunvalación con la que Escipión asedió la ciudad celtíbera.

Schulten parte de la información proporcionada por Apiano, quien en su Historia Roma$n a$ nos ha legado un texto extenso sobre la «Guerra de Numancia» que considera una copia abreviada de la supuesta monografía que sobre esta guerra escribió Polibio, testigo directo del asedio y destrucción de Numancia (Schulten, 1905: 67-70), supuestos ambos admitidos ciegamente por la bibliografía posterior (Capalvo, 1996: 25-28).

\footnotetext{
* Universidad Complutense de Madrid. E-mail: fmorales@pas.ucm.es.
} 
Sin embargo, se ha demostrado que la tradicionalmente admitida dependencia de la crónica de Apiano sobre la guerra numantina de Polibio no resulta sostenible. Nada avala, excepto la cita aislada de Cicerón (Ad fam., V, 12, 2), que Polibio escribiera un opúsculo sobre la caída de Numancia. Apiano pudo utilizar para la composición del relato del asedio de Numancia otras fuentes bien informadas y no suficientemente valoradas, como Sempronio Aselio, Rutilio Rufo o C. Fannio, entre otros (Astin, 1967: 4; Sancho Royo, 1973: 34-40; Goukowsky, 1997: XLI). Y, en contra del sentir de Schulten, es más que dudosa la presencia de Polibio en la toma de Numancia junto a Escipión (Díaz Tejera, 1972: 44; Sancho Royo, 1973: 25-26).

Aunque Apiano escribe su Historia Romana durante la primera mitad del siglo II d.C., en un contexto social, político e ideológico diferente del que existía en la Roma de Escipión y Polibio, muchos autores coinciden en que su obra parece fiable, en general, como resultado de la utilización de fuentes bien informadas (Astin, 1967: 4; Díaz Tejera, 1988: 1072; Gómez Espelosín, 1993: 26-30; Goukowsky, 1997: XXXIII-XLIII; Dobson, 2008: 41-43). Sin embargo, todavía hay quien cuestiona la fiabilidad del relato de Apiano (Jimeno, 2002: 173-174), aunque suponemos que con escasa convicción y sólo como arma de crítica irónica, ya que, curiosamente, hay ocasiones de todos conocidas (escenificaciones populares) en las que utiliza los textos del Alejandrino como garantía de rigor histórico y aval de credibilidad.

A pesar de tan extensa narración, y del razonable grado de certidumbre, siempre hemos sido conscientes de que en la obra de Apiano resalta la pobreza de detalles y la escasez de información (Dobson, 2008: 42), por lo que muchos aspectos de la guerra, asedio y destrucción de Numancia son necesariamente interpretables. La interpretación sólo es válida cuando el texto es confuso. Por ello, toda interpretación es bienvenida siempre que aporte un nuevo punto de vista. Este trabajo pretende ser un buen ejemplo de ello.

Además, el relato de Apiano sobre las guerras celtibero-lusitanas en general (Ib., 44-99), y sobre la construcción del cerco de Numancia en particular (Ib., 90-91), constituye la fuente exclusiva para esta parte de la historia. A pesar de sus deficiencias, estamos de acuerdo con Schulten cuando afirma que «el relato de Apiano figura entre las más sugestivas y exactas relaciones que poseemos de una guerra de la Antigüedad» (Schulten, 1945: 54).

Apiano menciona cronológicamente la construcción de dos campamentos, siete fuertes y, finalmente, dos fortines o puestos con la misión de cerrar el río. Sin embargo, Schulten (1905: mapa), «forzando» el sentido del texto interpretó desde el principio, antes incluso de realizar excavaciones, que la circunvalación de Numancia había consistido en siete campamentos y dos castillos ribereños. Posteriormente, condicionado por esta hipótesis inicial, localizaría siete campamentos en torno a la ciudad y dos castillos ribereños en dos puntos distintos del río, a pesar de que las excavaciones le aportaron una información que no se conciliaba con su interpretación inicial. Los informes anuales que fue publicando según avanzaban los trabajos de campo, reflejan cómo fueron cambiando sus interpretaciones. Pero en las conclusiones finales, publicadas en el volumen III de su monumental Numantia, mantendrá inalterada su teoría inicial, argumentando que Apiano no se había expresado con exactitud, y que los siete castillos no se habían añadido a los dos primeros campamentos, sino que los habían sustituido (Schulten, 1927: 20).

\section{SCHULTEN Y LOS DOS CASTILLOS RIBEREÑOS}

En 1905 Schulten publicó un análisis histórico-topográfico en el que comenta los textos de Apiano referentes a la guerra de Numancia así como la documentación que le había remitido el ingeniero español E. Saavedra. Aquí Schulten interpreta con una gran osadía, pero también con extraordinaria intuición, el pasaje del cierre del Duero. Así, afirma que 
Apiano no habla de dos obstáculos, pero de su crónica se deduce claramente que el río estaba cortado tanto aguas arriba como aguas abajo de la ciudad. [...] El corte de arriba debió situarse por debajo de la desembocadura del Tera, porque también hubo de cortar este río [...] El corte inferior hay que buscarlo donde se encontraban la línea del Duero y la línea del Merdancho (Schulten, 1905: 69-70).

Tras varias campañas de excavación Schulten identificó los siete campamentos en los lugares de Castillejo, Travesadas, Valdevorrón, Peña Redonda, Rasa, Dehesilla y Alto Real, y los castillos ribereños en los sitios de Molino de Garrejo y Vega de Garray, los dos puntos donde las obras de la circunvalación cortaban el Duero:

[uno en la zona sur,] entre Molino y Dehesilla, y evidentemente el pequeño campamento Molino es uno de los dos castillos de ribera citados por Apiano para la vigilancia del cerramiento, y otro en la norte en la línea de circunvalación entre Alto Real y la orilla oeste del río Tera, donde en el codo entre el río Duero y el río Tera parece encontrarse huellas de un castillo de ribera, Vega (Schulten, 1927: 87).

El castillo ribereño de Molino se encuentra situado sobre una terraza fluvial elevada unos $4 \mathrm{~m}$ sobre el curso actual del río cerca de la unión del Merdancho con el Duero. Fue excavado en 1906 y 1907 y, aunque no se hallaron restos de la muralla, Schulten le supone una extensión de 1,9 ha, mucho más reducida que las 6 ha que tienen por término medio los demás campamentos (Schulten, 1945: 203), diferencia que justificaba su adscripción.

Las excavaciones en Molino pusieron al descubierto cuatro medios cuarteles y cuatro cuarteles completos para la infantería, y los establos y dormitorios de un escuadrón que atribuyó a la caballería (Schulten, 1908: 151-152; 1909: 10-15; 1927: 232-238; 1945: 203) (figs. 1 y 2).

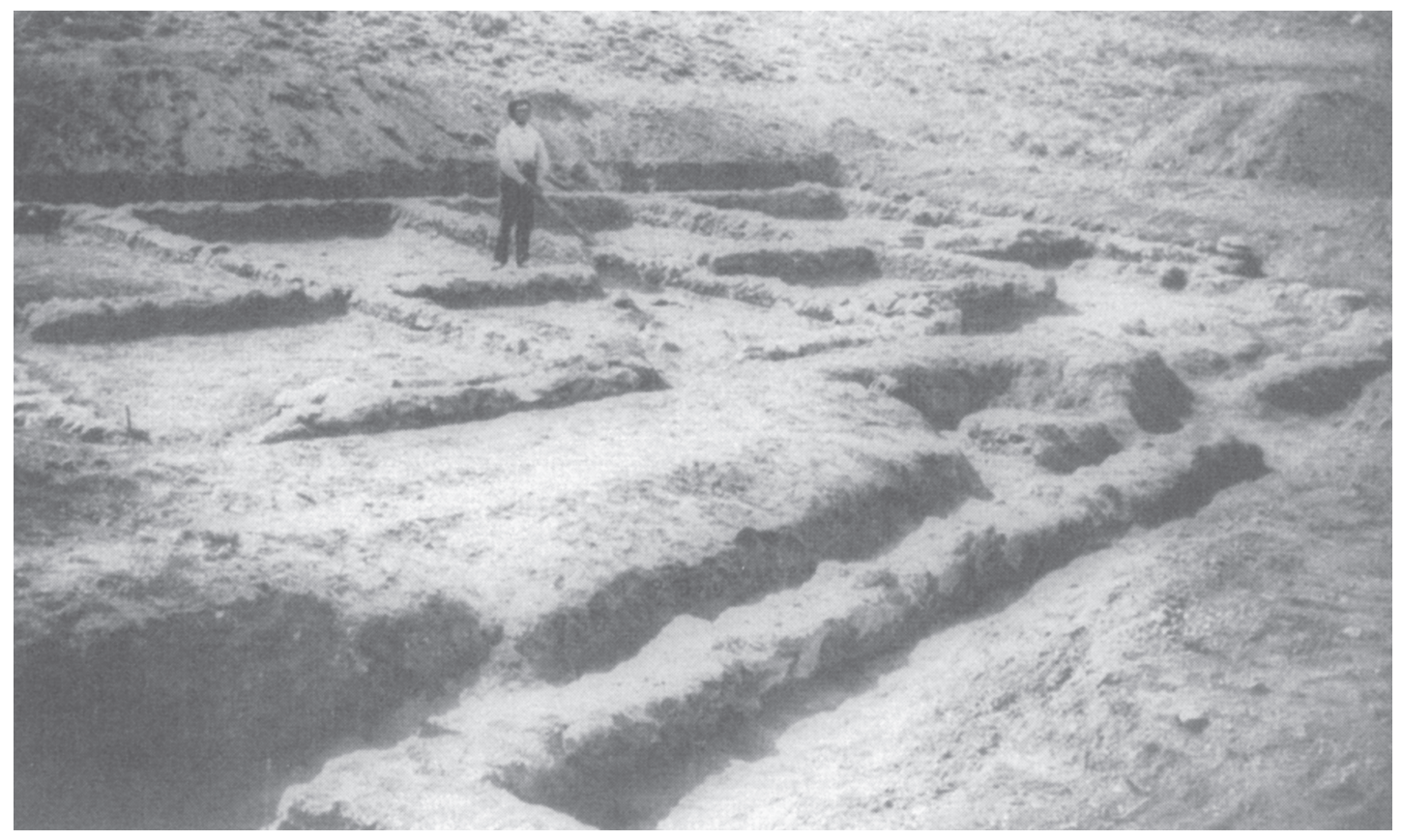

Figura 1. Vista parcial de los restos hallados en las excavaciones de 1907 en Molino (Schulten, 1927: lám. 13.2). 
Los restos muebles son escasos. Aunque Schulten no menciona ánforas ni cerámicas campanienses, Sanmartí presenta dos bordes de ánfora del tipo CC.NN., uno de ellos fruto de sus prospecciones (Sanmartí, 1985: 136.1 y 5), y dos fondos de cerámica campaniense A (Sanmartí y Principal, 1997: 51) conservados en el RGZM. Por el contrario, Luik (2002: 218.646 y 200.290), en la revisión que hace de los materiales del RGZM, además del ánfora CC.NN. casi completa de Molino, únicamente menciona un fondo de campaniense. Haeberlin (1929: 243.150 y 246.191) cita un denario de plata y un as de Sethisa que posteriormente Romagosa (1972: 94) asigna a Sekaisa. Ambos son citados por Hildebrant (1979: 247). En cuanto a armas, se hallaron un pilum de punta barbada, una hoja de puñal, varios regatones y algunos objetos variados: fíbulas, dos molinos de mano completos, un compás... (Schulten, 1909: 15; 1927: 238; 1945: 203; Luik, 2002: 14).

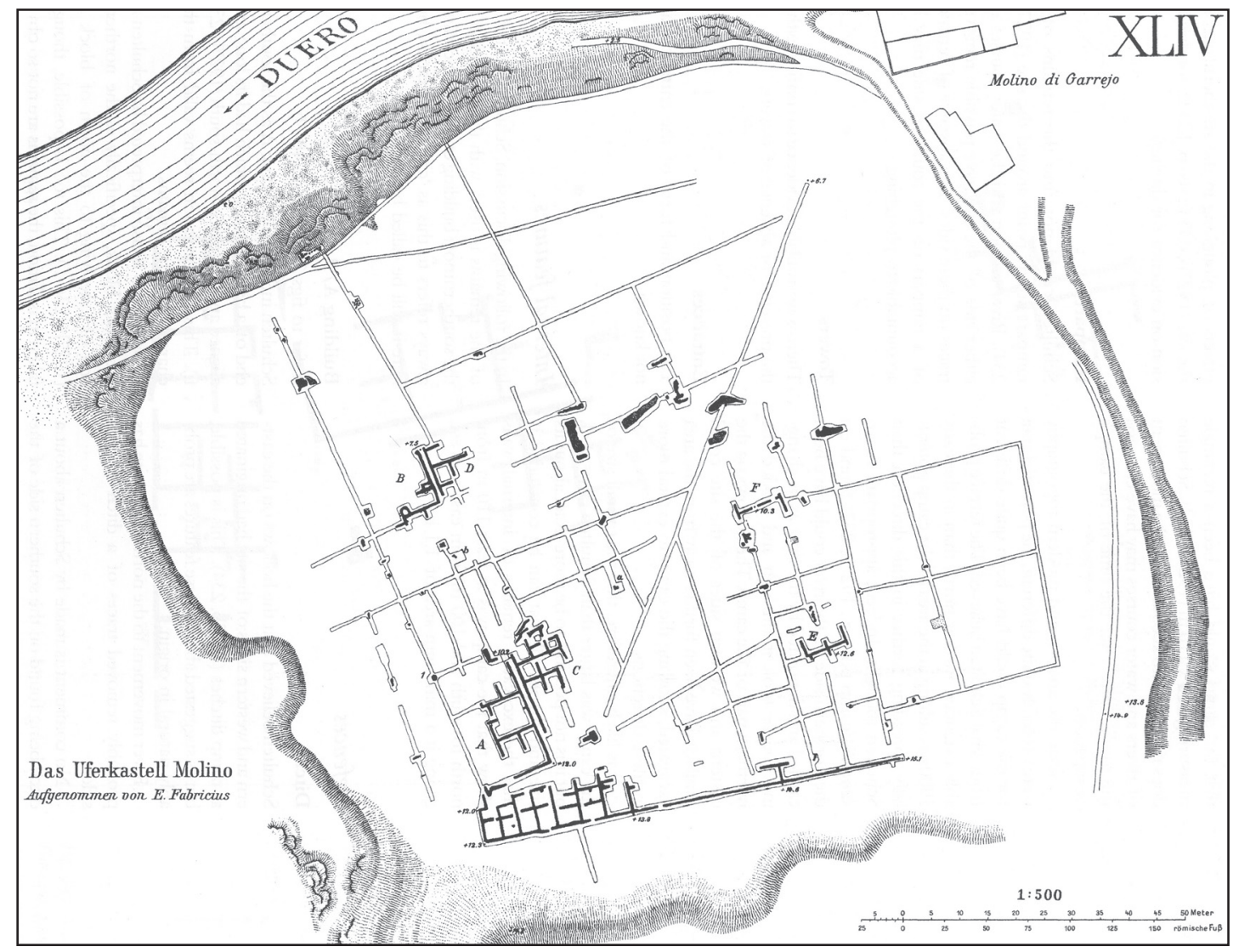

Figura 2. Plano general de las excavaciones realizadas en Molino (Schulten, 1927: plano XLIV).

El otro castillo ribereño, Vega, se localiza sobre una pequeña terraza fluvial que se alza unos $4 \mathrm{~m}$ en la confluencia de los ríos Duero y Tera. Su extensión habría sido semejante a la de Molino (Schulten, 1927: 240).

Las excavaciones arqueológicas de Schulten en este paraje tuvieron lugar en 1906 y 1907, y en ellas se hallaron algunos restos de muros muy alterados y una muralla (Schulten, 1908: 149-150; 1927: 240; 1945: 204). En cuanto a restos muebles, de Vega proceden ánforas (Schul- 


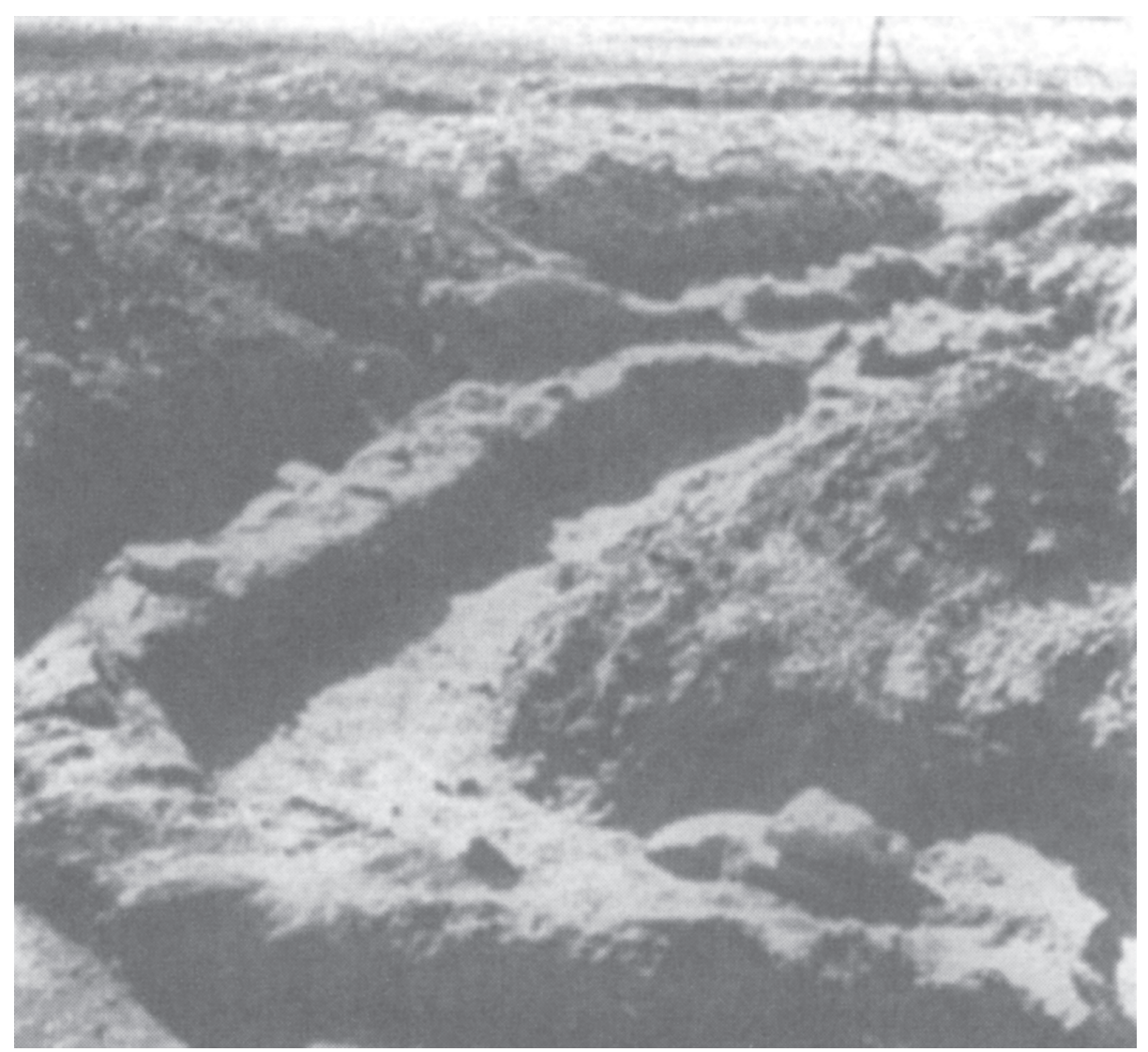

Figura 3. Muros hallados en las excavaciones realizadas en 1906 en Vega (Schulten, 1927: lám. 33.5).

ten, 1927: 240; 1945: 204), un fragmento de cerámica campaniense además de otros tipos cerámicos (Sanmartí y Principal, 1997: 59.3; Luik, 2002: 14) (figs. 3 y 4).

Esta interpretación de Schulten de los textos de Apiano referente al cierre del Duero, que él creyó ver confirmada por sus excavaciones, ha sido mantenida sin cuestionamiento (Taracena, 1941: 81-82; Bosch y Aguado, 1955: 165-185; Capalvo, 1996: 190), llegando recientemente a interpretarse, sin ningún fundamento e ignorando el relato de Apiano, que los castillos ribereños se construyeron en lugar de los puentes (Jimeno, 2002: 166; Jimeno y otros, 2002: 87) admitiendo, al parecer, que Escipión habría intentado tender dos puentes en el Duero, y ante la imposibilidad de tal empresa, habría construido, en la unión de los ríos Tera y Merdancho al Duero, los dos castillos ribereños, instalando en ambos lugares los mecanismos de cierre descritos por Apiano, tal y como proponía Schulten (1937: 297) en las F.H.A.. Sin embargo, este planteamiento no es sostenible.

En una reciente publicación Dobson (2008: 404-405) opina que faltan evidencias arqueológicas para considerarlos escipiónicos, o incluso romanos, y que parece mejor dejar fecha y función como inciertos. No obstante, siguiendo a Schulten, sugiere que los fortines de bloqueo habrían estado situados a ambos lados del río cerca de Molino y Vega, y que la erosión del Duero desde tiempos de Escipión explicaría la ausencia de restos. 


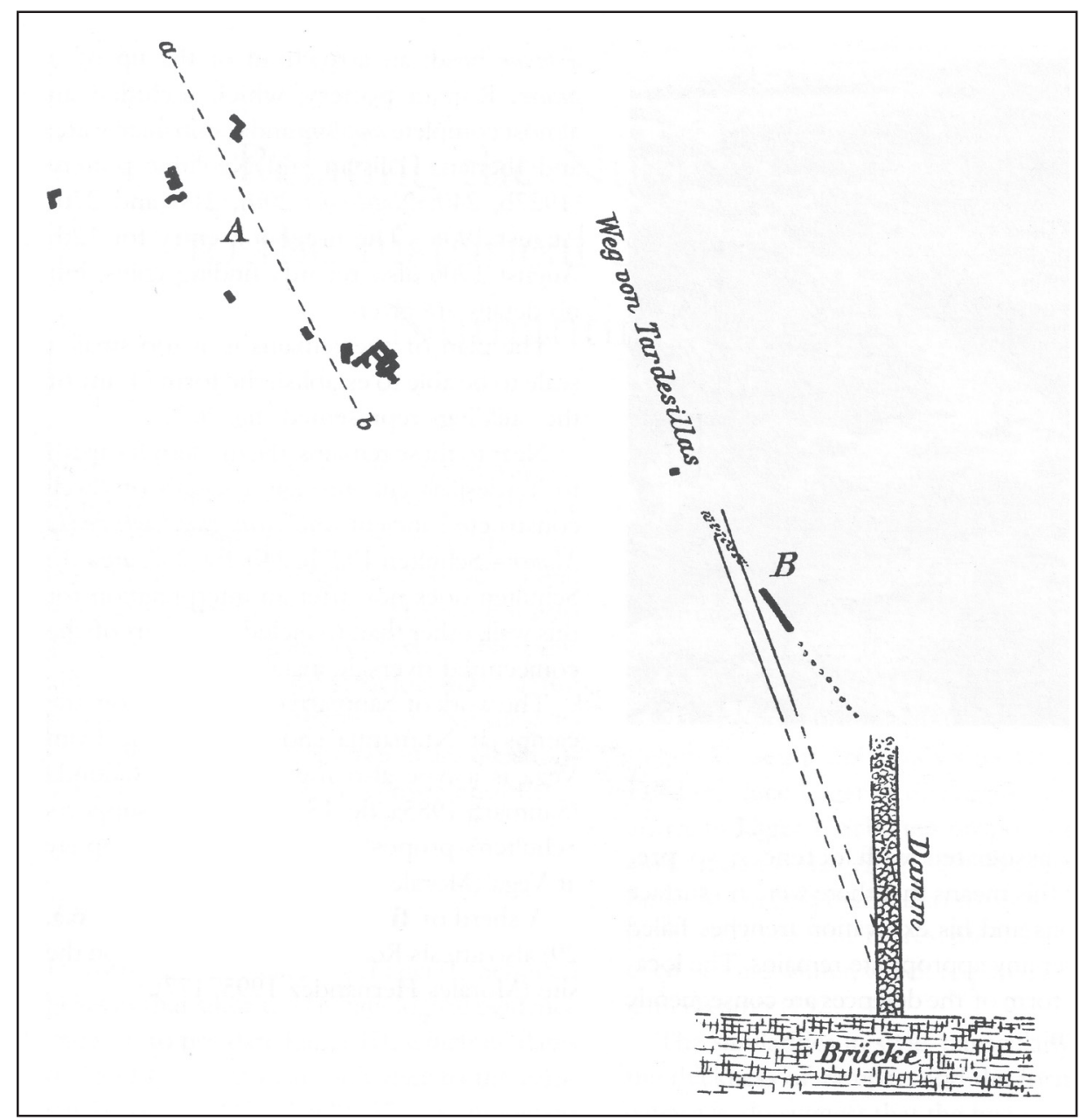

Figura 4. Plano general con los restos hallados en Vega (Schulten, 1927: plano XLVII)

\section{MOLINO Y VEGA: FUERTES DE LA CIRCUNVALACIÓN}

Schulten (1927: 230) supuso que entre Dehesilla y Peña Redonda, por la distancia entre ellos, debía existir un campamento, y que había que buscarlo sobre las alturas del Merdancho siguiendo el esquema que había observado en otros puntos de la circunvalación. Pero la ausencia de construcciones, o restos de ellas, así como del muro de la circunvalación, le hicieron pensar que la línea del cerco no corría por las alturas, lo que constituía una total anomalía, sino por el valle, cerca del río Merdancho, y que Molino podía ser el buscado campamento, a pesar de su reducido tamaño (Schulten, 1908: 152; 1909: 10). Pero sus investigaciones por las alturas descubrieron en Rasa un talud plano pero definido, de unos $300 \mathrm{~m}$ de longitud, dotado de dos puertas con titulus, correspondiente a la muralla de un campamento (Schulten, 1927: 230).

Sin embargo, Schulten parece haber tenido algunas dudas de que Rasa fuera parte de los trabajos del sitio de Escipión. Él reparó en que el carácter de la muralla era ligeramente diferente al resto de las obras del cerco de Escipión, y por tanto no podía pertenecer a ellos; de hecho, compara los restos de la muralla de Rasa con los que él encontró en Almazán, y no con 


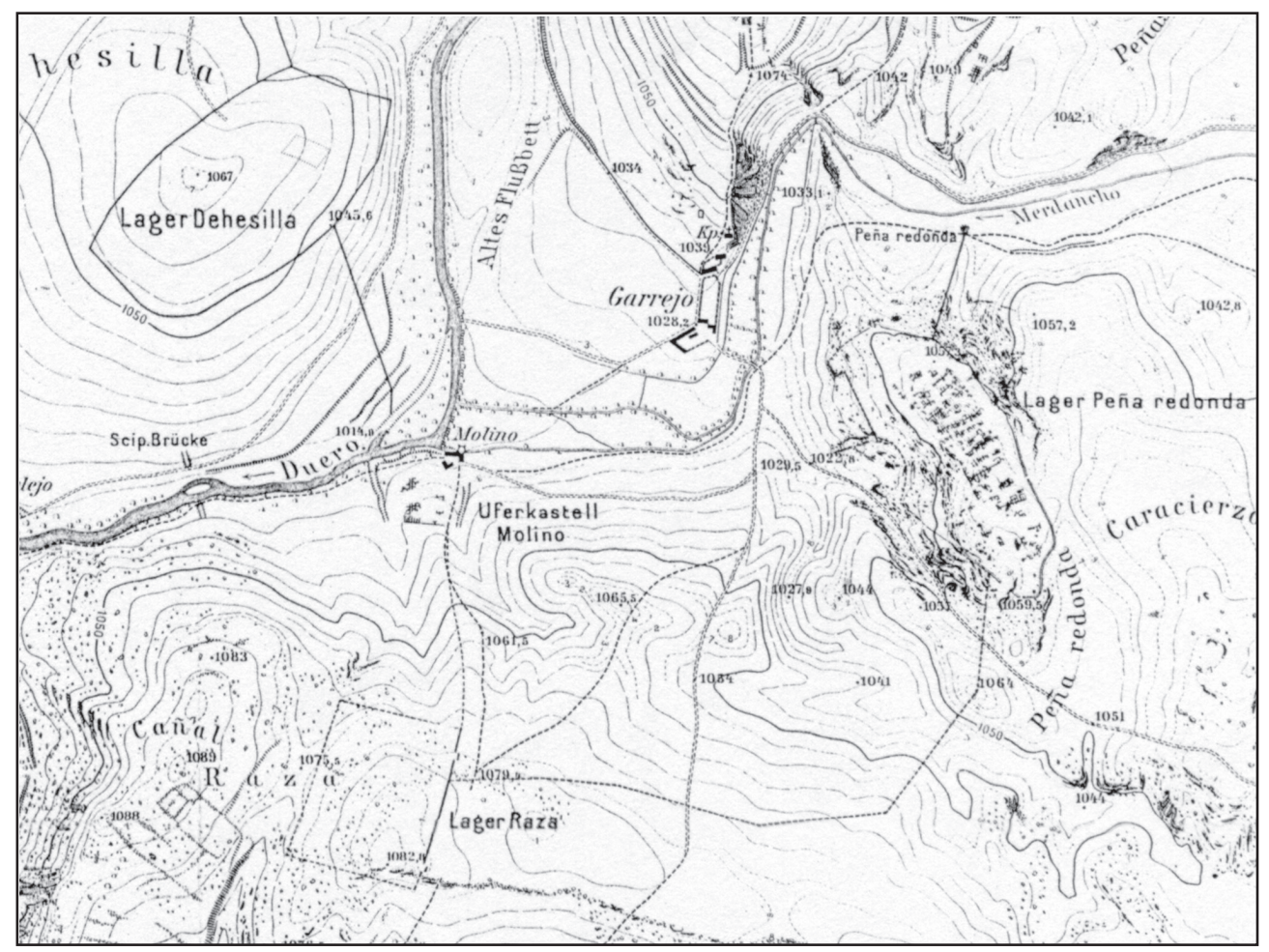

Figura 5. La línea del Merdancho y la circunvalación escipiónica, según Schulten (¿1927?: Plano 1).

éstos del asedio de Numancia (Schulten, 1927: 231). A pesar de todo, incluye Rasa como parte de los trabajos de circunvalación (fig. 5).

Incluso llegó a plantearse la idea de que Rasa hubiera sido un campamento anterior a Escipión, pero la rechaza porque Rasa queda precisamente a medio camino entre Peña Redonda y Dehesilla y, por tanto, debía formar parte del cerco de Escipión (Schulten, 1927: 230). Sin embargo, es un argumento débil para que él no tuviera en cuenta el fuerte de Molino entre Peña Redonda y Dehesilla, ya que la distancia entre todos los campamentos del cerco es de hecho irregular.

La línea de la circunvalación mostrada en los planos publicados por Schulten es completamente hipotética entre los campamentos de Peña Redonda y Rasa, y entre Rasa y Molino. De hecho, él consideró, y después rechazó, la posibilidad de que corriera directamente de Peña Redonda a Molino cerca del Merdancho (Schulten, 1927: 230).

Pero poniendo Rasa fuera del contexto del cerco de Escipión se explicaría por qué Schulten (1927: 231) no encontró ningún rastro de la circunvalación en torno a Rasa, existiendo la posibilidad de que efectivamente ésta se encontrara más al norte.

Nuestras exploraciones se trasladaron a la terraza más baja, constatando la presencia de fragmentos de ánfora, cerámicas indígenas, comunes romanas y la piedra de un molino. Sin embargo, y a pesar de las intensas prospecciones, los surcos producidos por una plantación de pinos han alterado el terreno de tal manera que resulta imposible determinar la existencia del muro de circunvalación. No obstante, los materiales descritos demuestran finalmente que la línea de vallum corría cerca del río Merdancho por la zona baja, entre Peña Redonda y Molino, confirmándose por tanto que el campamento de Rasa no formaba parte del cerco de Numan- 


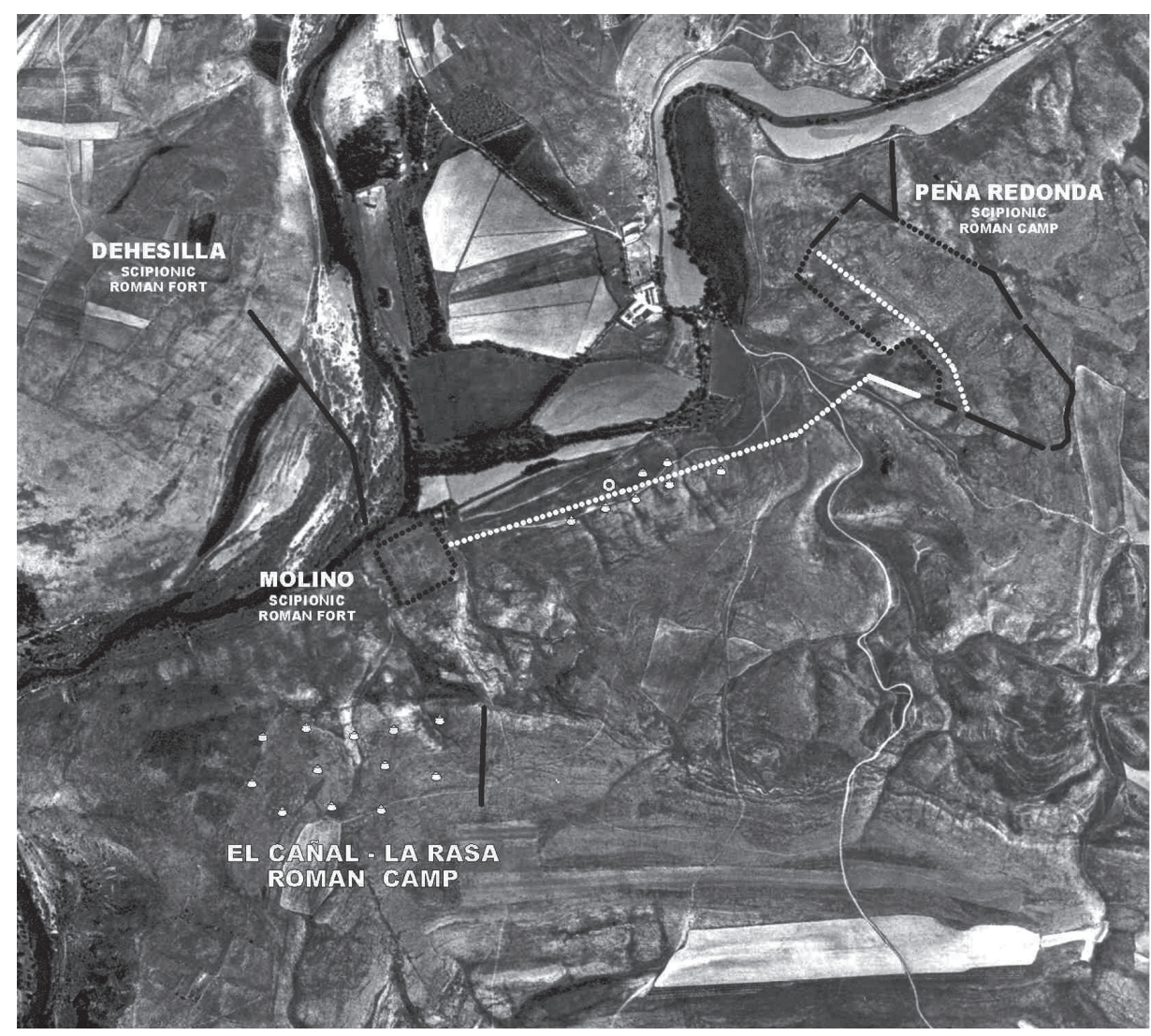

Figura 6. Fotografía aérea de la línea del Merdancho con el nuevo trazado de circunvalación propuesto (Morales Hernández y Dobson, 2005: fig. 3).

cia, y que Molino no fue uno de los dos castillos ribereños, sino uno de los siete fuertes de la circunvalación (Morales y Dobson, 2005) (fig. 6).

En consecuencia, Schulten había identificado los dos «castillos ribereños» en los lugares de Molino y Vega; sin embargo, por la extensión y los hallazgos que ofrecieron al ser excavados, tanto uno como otro presentan la suficiente entidad para ser considerados, de acuerdo con la reinterpretación formulada, dos de los siete fuertes de la circunvalación, quedando así liberados de la condición a la que injustificadamente se les había rebajado.

\section{EL PUENTE DE ESCIPIÓN Y EL CIERRE DEL DUERO}

En 1906 Schulten descubrió a unos 400 m de Molino, aguas abajo del Duero, al pie de los cerros de Cañal y Dehesilla y cerca del cauce del río, los restos de un ancho dique de unos $5 \mathrm{~m}$ de altura al que correspondía sobre la pendiente de Dehesilla, situada en la orilla opuesta, un dique semejante (Schulten, 1908: 151-152) que inmediatamente identificó como pertenecientes al puente de Escipión:

ambos diques [...] no pueden ser otra cosa que restos del puente sobre el Duero que Escipión intentó construir pero que debido a la creciente corriente nunca llegó a terminar (Schulten, 1927: 87) (fig. 7). 


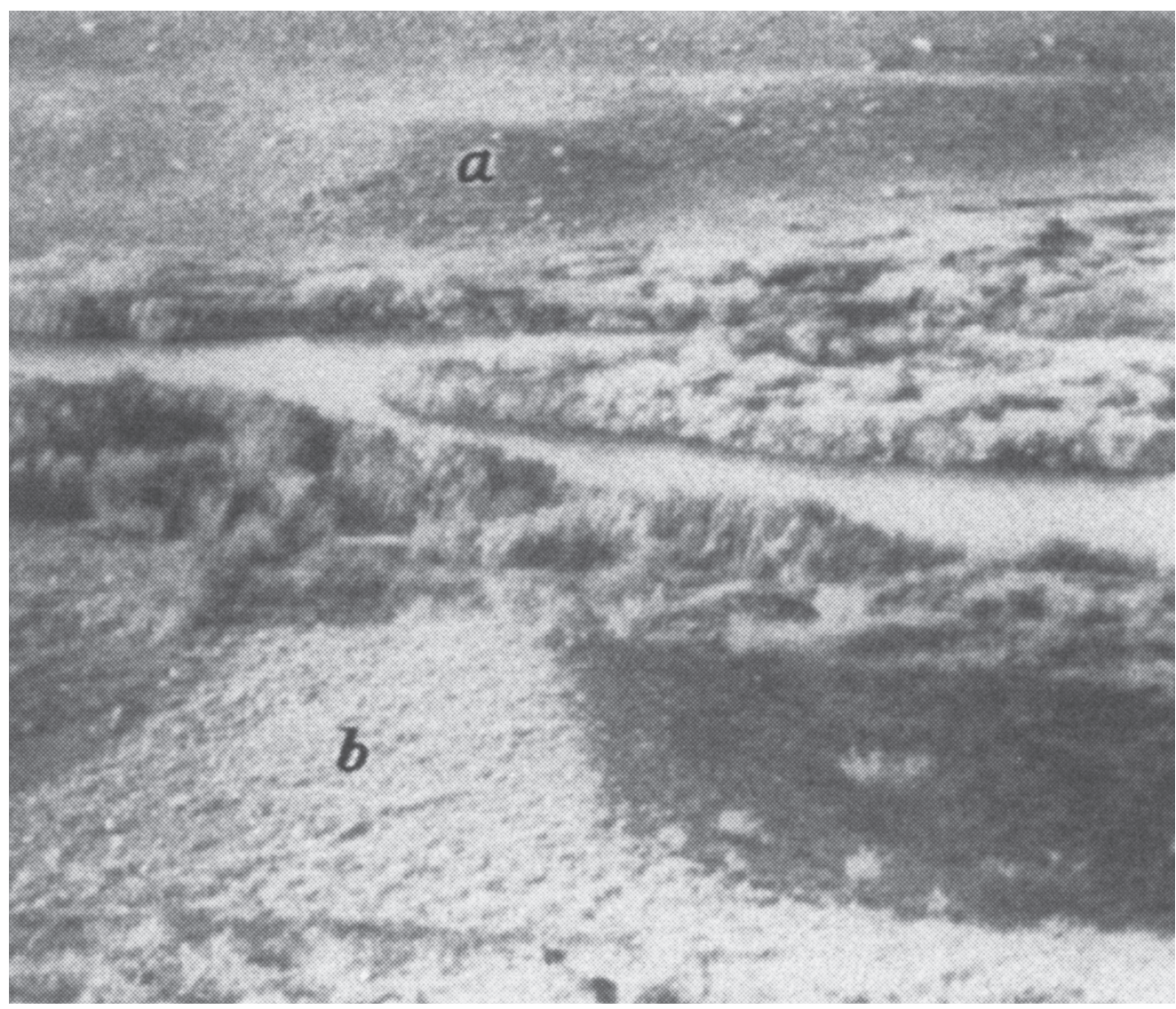

Figura 7. Vista del Duero desde el lado de Cañal, con los dos diques $(a, b)$ que Schulten consideró restos del puente que Escipión no pudo construir sobre el Duero (Schulten, 1927: lám. 2.2).

Sin embargo, Schulten juzga que las obras del puente no se encuentran en su lugar lógico, que sería la línea de circunvalación, sino desplazadas unos $400 \mathrm{~m}$ aguas abajo de ésta, donde más se aproximan los cerros de Dehesilla y Cañal; allí el valle únicamente tiene entre 70 y $80 \mathrm{~m}$ de ancho. Además de la cercanía de las orillas, el lugar era el adecuado según Schulten (1927: 87) por las islas formadas por el río, que considera pudieron haber sido utilizadas para apoyo de un pilar del puente.

La longitud final del puente habría sido de $115 \mathrm{~m}$, y habría necesitado más pilares que el central, dos en cada lado, con una distancia variable entre cada uno de ellos de 17 a $25 \mathrm{~m}$ según su situación. El pilar central habría tenido una altura de $7 \mathrm{~m}$, los siguientes a cada lado $6 \mathrm{~m}$ y los dos más alejados del central, pero ya cerca de los diques, entre 4 y $5 \mathrm{~m}$ (Schulten, 1927: 88).

El dique de la orilla izquierda, el de Cañal, es el mejor conservado: tiene en la base $45 \mathrm{~m}$ de longitud por 30 de anchura, y en la coronación $30 \mathrm{~m}$ de longitud por 10-15 m de ancho. El interior de este dique se encontraba reforzado por tres gruesos muros de entre 0,80 y $1,50 \mathrm{~m}$ anclados entre sí mediante uno o varios muros traviesos.

El dique de la orilla derecha, el de Dehesilla, es más plano, como la misma pendiente de la colina y apenas destaca. No obstante, ambos se encuentran muy nivelados, con una diferencia de altura de apenas $20 \mathrm{~cm}$ (figs. 8 y 9). 


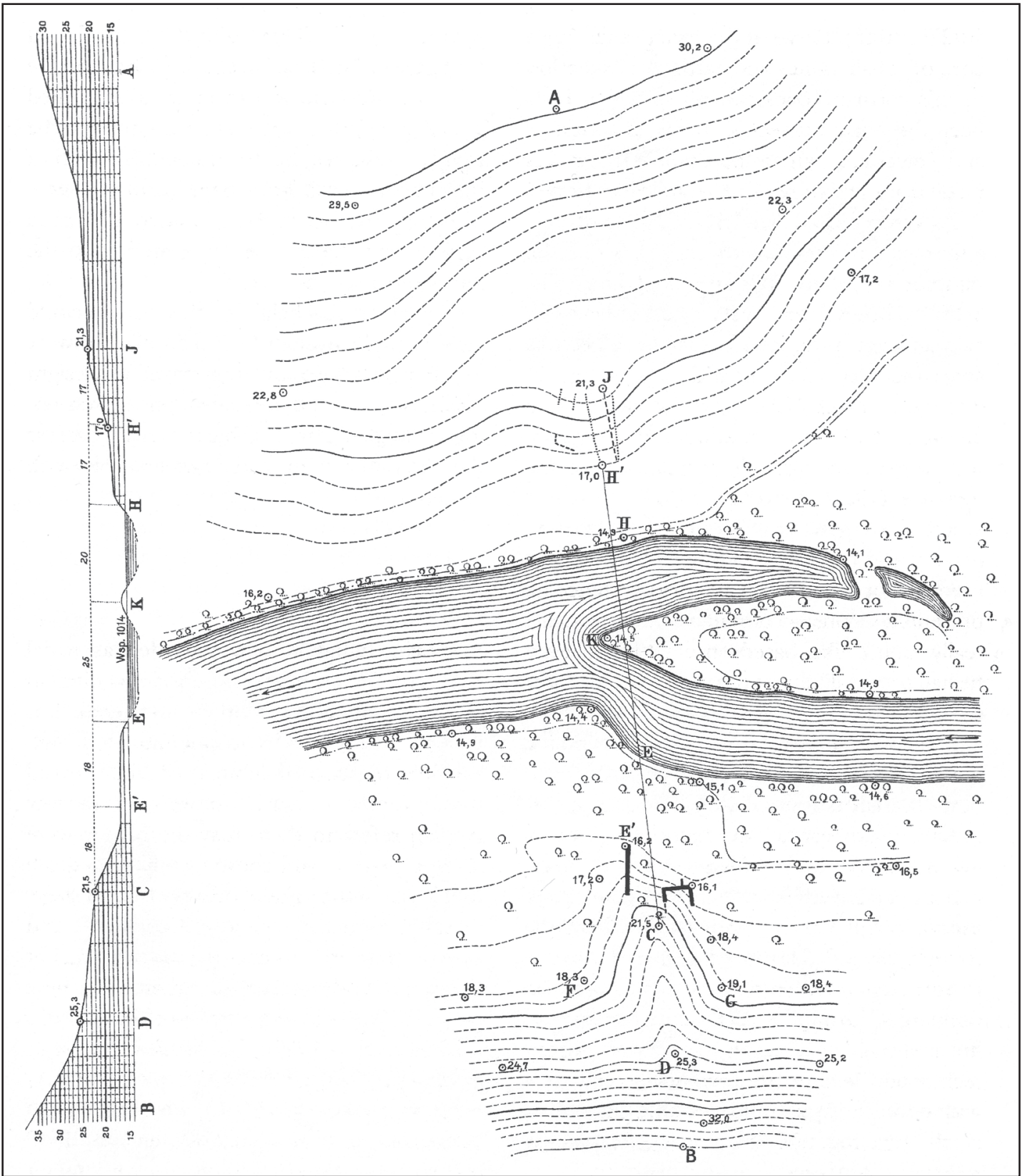

Figura 8. Plano y sección del Duero con los restos de las obras asociadas por Schulten con el puente de Escipión (Schulten, 1927: plano IX).

Al considerar Schulten que estos diques se correspondían con los restos del fallido intento de construir un puente, el cerramiento del río con los mecanismos descritos por Apiano debía encontrarse cerca del paraje de Molino:

El cerramiento sur debe haberse colocado entre Molino y Dehesilla y evidentemente, el pequeño campamento Molino es uno de los dos castillos de ribera citados por Apiano para la vigilancia del cerramiento (Schulten, 1927: 87). 


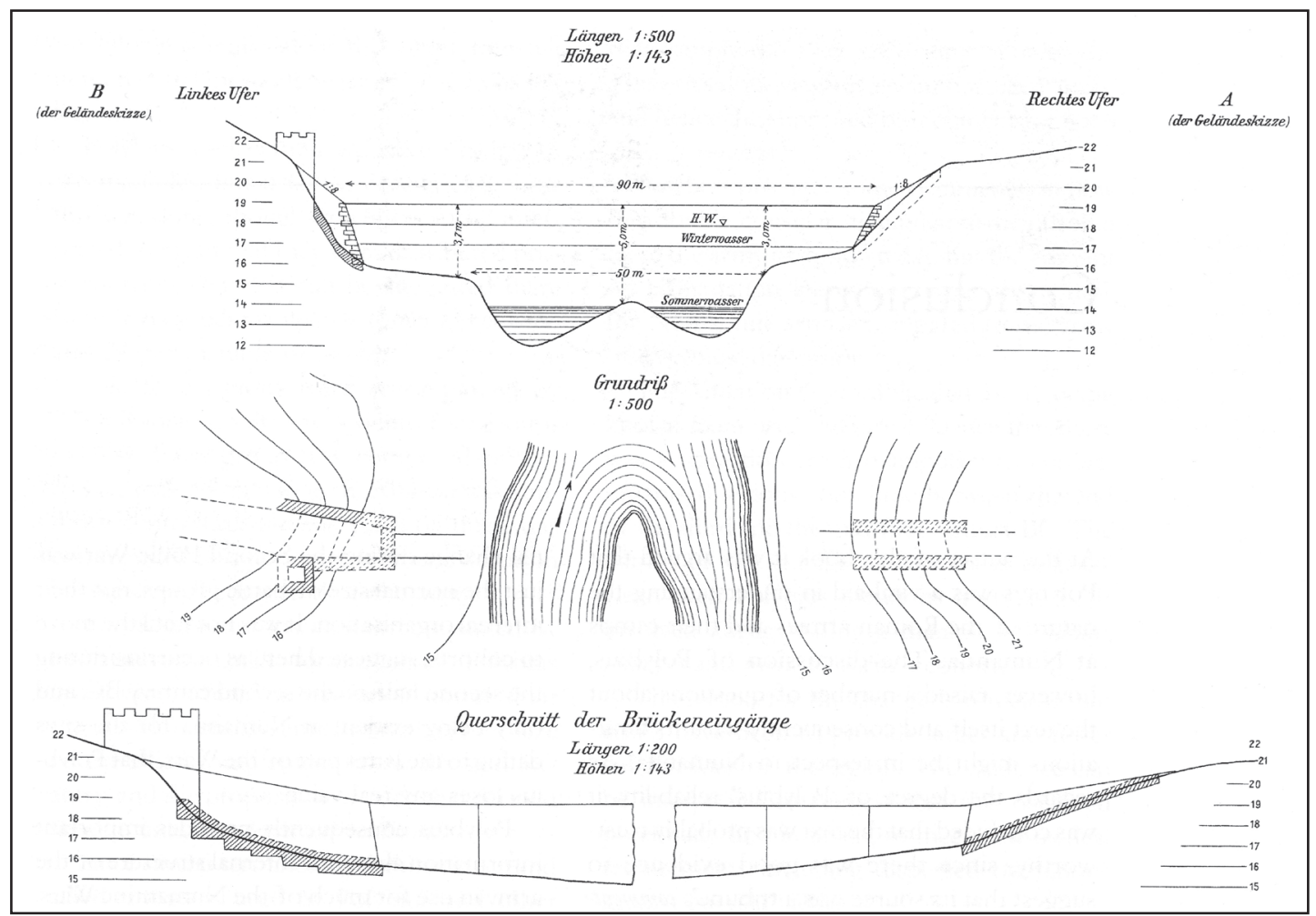

Figura 9. Plano y sección de las dos riberas del Duero con los restos del supuesto puente de Escipión (Schulten, 1927: plano X).

En consecuencia, Schulten acepta el texto de Apiano, pero interpretando que a Escipión le había sido imposible tender un puente sobre el río, e insiste en considerar estos diques como restos de una obra inacabada sobre la base de la disposición de éstos frente a la isla, por lo que concluye que establecer una relación entre los diques y el cierre descrito por Apiano debe ser rechazado (Schulten, 1908: 152). Sin embargo, el argumento es débil como para no tener en cuenta esta posibilidad, ya que la configuración actual del río (con la isla) no refleja necesariamente la fisonomía que pudo tener en el momento del asedio.

\section{EL TEXTO DE APIANO Y SUS INTERPRETACIONES}

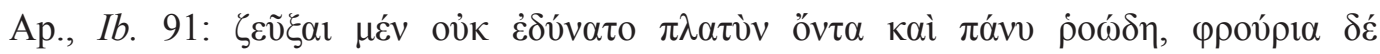

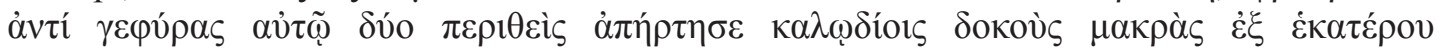

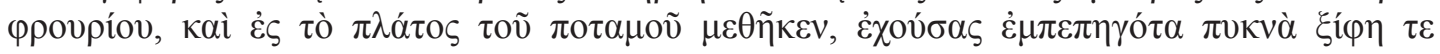

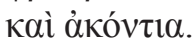

Traemos aquí varias traducciones al castellano del texto de Apiano:

- SAaVedra, 1881 (sobre traducción de don Ambrosio Rui Bamba, 1852):

No pudiendo Escipión echar un puente al río por su ancha e impetuosa corriente, levantó por equivalente dos fuertes, y atando con maromas desde el uno al otro unas vigas largas, las tendió sobre la anchura del río. En estas vigas había clavado espesos chuzos y saetas. 
- SCHULTEN, 1937:

Tender un puente no era factible, por la anchura y violencia del río. En lugar de un puente, Escipión construyó dos castillos; desde ellos tendió unas vigas, atadas con cuerdas sobre la parte ancha del río; clavados en ellas había muchos hierros agudos y dardos.

- SAncho Royo, 1980:

Como no podía unir sus orillas por ser ancho y muy impetuoso, construyó dos torreones, en vez de un puente, uno en cada orilla y desde cada uno colgó, con cuerdas, grandes tablones de madera que dejó flotar a lo ancho del río, y que llevaban clavados numerosos dardos y espadas.

— Gómez EsPelosín, 1993:

Como no podía unir sus dos orillas, dado que era ancho y de corriente violenta, tras situar en sus dos orillas dos puestos fortificados, en lugar de puente, hizo suspender mediante pequeñas cuerdas las vigas a cada uno de los puestos y las soltó a lo ancho del río, llevando clavadas de forma apretada espadas y dardos.

Podemos ver que de casi todas las versiones de la traducción del texto del autor alejandrino se desprende que los dos fortines se encontraban uno enfrente del otro, en el mismo punto del río.

La versión de Schulten es imprecisa y equívoca: «Escipión construyó dos castillos; desde ellos tendió unas vigas...»; con ella en la mano se entiende y justifica su teoría, según la cual los dos castillos ribereños citados por Apiano serían totalmente independientes y se encontrarían en los lugares de Molino y Vega, separados uno del otro por una distancia de más de $2 \mathrm{~km}$. De hecho, interpreta que «Apiano no habla de dos obstáculos, pero de su crónica se deduce claramente que el río estaba cortado tanto aguas arriba como aguas abajo de la ciudad» (Schulten, 1905: 69). Por tanto, el río se habría cerrado en dos puntos de la circunvalación. Y según esta interpretación, cuando Schulten dice que «desde ellos tendió unas vigas...» realmente está diciendo que «desde (cada uno de) ellos» se habrían colgado con cuerdas las vigas. Esto posiblemente habría requerido una sujeción de las cuerdas en la orilla opuesta para que las vigas quedaran centradas en el río, por lo que se habrían requerido no dos, sino cuatro puestos para atender los mecanismos. Y Apiano únicamente habla de dos fuertes. De este problema ya se percató Schulten, pues al describir el castillo ribereño de Vega comenta que «no se pudo averiguar si existía una cabeza de puente en la otra orilla» (Schulten, 1927: 240)

En el resto de las traducciones, en unas mejor que en otras, pero sin duda en todas ellas, se interpreta correctamente la situación de los dos torreones: «construyó dos torreones, uno en cada orilla» (Sancho Royo); «tras situar en sus dos orillas dos puestos fortificados» (Gómez Espelosín), o incluso en la versión más antigua presentada por Saavedra, «y atando con maromas desde el uno al otro unas vigas...», se entiende claramente que los fuertes se encontraban uno en cada orilla, el uno enfrente del otro.

\section{ANÁLISIS SINTÁCTICO}

Con él tratamos de ver, mediante un proceso de segmentación, la forma en que las palabras de una estructura se relacionan entre sí, y la función que cada una realiza en la oración. El objetivo es obtener los conceptos básicos del texto, su comprensión.

En la narración de Apiano hay algunas oraciones y palabras clave que permiten aclarar las actuaciones de Escipión, y la confusa visión que ofrece Schulten, permitiendo reinterpretar y corregir sus conclusiones ${ }^{2}$.

2 Nuestro agradecimiento al Prof. D. Carlos García Gual, Catedrático de Griego de la Universidad Complutense de Madrid y Premio Nacional de Traducción 2002, por sus orientaciones, consejos y sugerencias. 


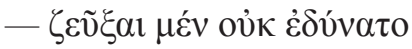

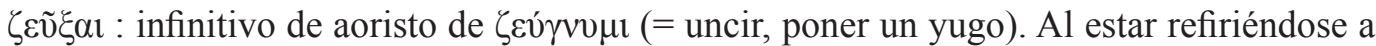

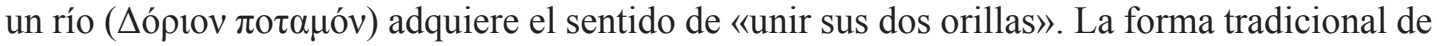
«uncir», «poner un yugo» a un río, en definitiva, de unir sus orillas, es mediante un puente. En el texto queda sobreentendido. No obstante, si aún así nos preguntásemos cómo pretendía Escipión ponerle un yugo al río, Apiano lo explicita más adelante cuando, siendo inviable esta primera opción por las circunstancias que concurrían en el río, plantea una segunda opción:

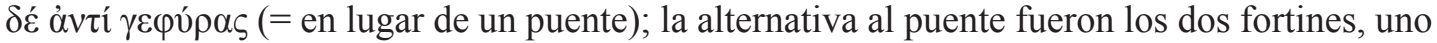
en cada orilla.

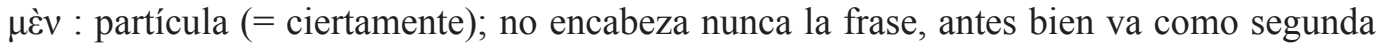
palabra de ella. Puede estar en correlación con otras partículas que actúan como segundo miembro, en nuestro caso con $\delta \dot{\varepsilon}$ (= ciertamente... pero).

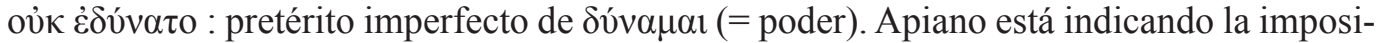
bilidad de Escipión de tender un puente sobre el río por ser ancho y de corriente violenta. En

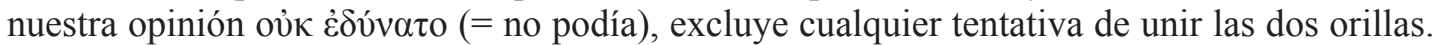
Escipión descartó a priori esta opción ante la naturaleza del río.

Sin embargo, Schulten interpreta que Escipión intentó construir un puente, pero «no pudo». Así, afirma «nicht überbrücken konnte» (1905: 69; 1927: 87). Y como prueba de ese fallido intento presenta los dos diques que descubrió cerca de Molino. Y la isla del río.

«No podía» (pretérito imperfecto), «no pudo» (pretérito perfecto). Ambos tiempos tienen valor modal de indicativo y una perspectiva modal de pretérito. Sin embargo, no aluden a las mismas situaciones. Hay una diferencia, aunque ambos se refieren a hechos efectivos. El pretérito imperfecto abarca una zona temporal más amplia, por lo que posee un sentido durativo, «no terminativo», mientras que el pretérito perfecto tiene un sentido puntual, «terminativo» señalando la consumación de la acción (Alarcos, 1994: 161).

Pero en ocasiones, con la forma «no terminativa» se expresa también el llamado «pretérito de conato» o «de simple tentativa», en el cual la prevista intención de producirse un hecho queda anulada mediante su negación (Alarcos, 1994: 163). El valor inactual (negativo) de este pasado puede interpretarse como la negación de la factualidad del vínculo sujeto-verbo. En estos casos, el hablante presenta la acción verbal como irreal, para indicar un deseo irrealizable (Alfageme, 1988: 214; Berenguer, 2003: 207).

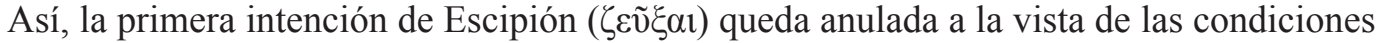

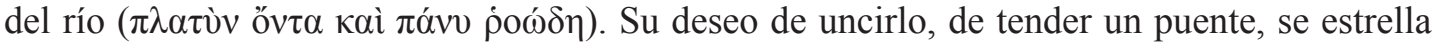
con la realidad del río, por lo que no llega a producirse intento, sólo existe intención truncada.

—

$\delta \varepsilon ́$ : partícula postpositiva en correlación con $\mu \varepsilon^{\prime} v$ (= pero).

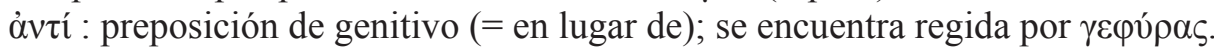

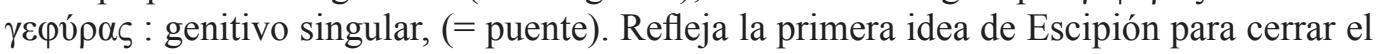

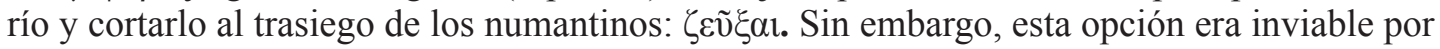

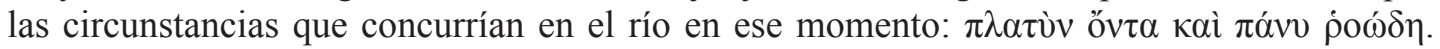
La alternativa al puente fueron los dos fortines.

$\alpha$ $\tau \tilde{\varphi}$ : adverbio (= en torno a él); va acompañando a $\pi \varepsilon \rho 1 \theta \varepsilon i \varsigma$ y se está refiriendo al río.

$\pi \varepsilon \rho \imath \theta \varepsilon i \zeta$ : participio de aoristo de $\pi \varepsilon \rho \iota \tau i ́ \theta \varepsilon \mu \iota$ (= rodear, ceñir, poner alrededor) (habiendo rodeado). Se emplea en el sentido de «cercar, asediar» el río mediante los dos fortines ( $\varphi \rho o v ́ p ı \alpha ~ \delta v ́ o)$, instalando uno en cada orilla ( $\alpha$ $\tau \tilde{\omega})$ con lo que se conseguía cerrarlo. Quizá

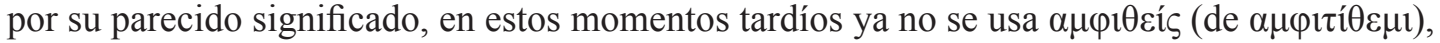


cuyo empleo tiene el sentido de «colocar, instalar a uno y otro lado», un significado más abierto que el empleado intencionadamente? por Apiano.

A partir de aquí se pueden extraer algunos conceptos que facilitan la comprensión del texto:

- Apiano nos transmite el primer impulso de Escipión: uncirlo, tender un puente, cerrar el río al tránsito de los numantinos.

- El río era ancho y de corriente rápida, por lo que desistió. Su deseo era irrealizable.

- La segunda opción de Escipión para cerrar el río fue construir dos fortines.

- Los fortines estaban uno en cada orilla ( $\alpha$ $\tau \tilde{\omega})$ con la intención de cercarlo ( $\pi \varepsilon \rho \imath \varepsilon \varepsilon i ́ \varsigma)$.

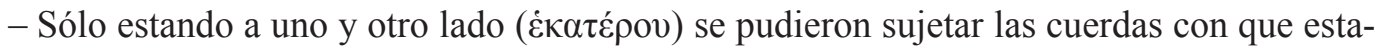

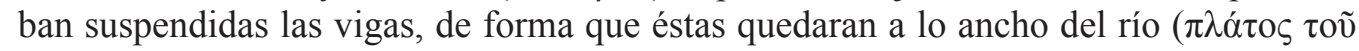
$\pi \circ \tau \alpha \mu \mathrm{o} \tilde{)})$, cubriendo fundamentalmente la parte central, ya que las zonas próximas a las orillas podían ser batidas con arqueros, honderos y armas arrojadizas.

Estas puntualizaciones permiten una traducción literal del texto griego:

Ciertamente no podía uncirlo por ser ancho y de corriente violenta, pero en lugar de un puente habiendo puesto alrededor dos fortines en torno a él, colgó con cuerdas pequeñas a uno y otro fortín grandes vigas de madera que soltó a lo ancho del río, teniendo clavadas apretadas espadas y dardos.

Y, a partir de ella, una traducción libre:

Ciertamente no podía tender un puente por ser ancho y de corriente rápida, pero habiendo colocado dos fortines uno en cada orilla en lugar de un puente, colgó con cuerdas, de cada uno de los fortines, grandes vigas de madera que soltó a lo ancho del río, llevando clavadas de forma apretada espadas y dardos.

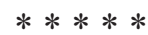

En anteriores trabajos hemos expuesto nuestras discrepancias con la interpretación de Schulten sobre la circunvalación de Numancia descrita por Apiano (dos campamentos, siete fuertes y dos fortines). Nuestra reinterpretación de los hallazgos del arqueólogo alemán tiene su confirmación arqueológica en los restos que han aparecido en torno a la ciudad celtíbera, fruto unos de las excavaciones de Schulten, y otros de las prospecciones e investigaciones actuales (Morales, 2004; 2006; e.p.; Morales y Dobson, 2005; Dobson, 2008).

Si Molino y Vega fueron considerados por Schulten los dos «castillos ribereños» citados por Apiano para cerrar el río, actualmente son considerados como dos de los siete fuertes de la circunvalación (Morales, 2004: 255; e.p.; Morales y Dobson, 2005: 108; Dobson, 2008: 413). La construcción de los siete fuertes y su posterior unión a los dos campamentos mediante un vallum conformaron el cerco de Numancia. Por tanto, la instalación de los fuertes de Molino y Vega junto al río Duero fue una decisión intencionada en la distribución de los siete fuertes en torno a Numancia, pero no relacionada con el cierre del río como propuso Schulten (1905: 69), sino con la vigilancia y el control del mismo en aquellos puntos donde el trazado del vallum lo cortaba. La construcción de los dos fortines con los mecanismos que cierran el río es posterior al levantamiento de la circunvalación (Ib. 90). 
Schulten incluye los castillos ribereños que cerraban el Duero en la línea de circunvalación, precisamente en los dos puntos donde ésta interseca con aquél, en Molino y Vega. Pero esta inclusión en la línea de vallum con la misión de cerrar el río es difícil de sustentar, ya que en estos dos lugares el valle es demasiado ancho (120 m en Molino y $150 \mathrm{~m}$ en Vega), y

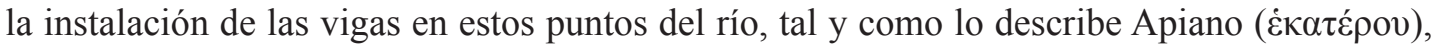
plantearía serias dificultades si no se admite un contrapunto en la orilla opuesta donde sujetar las cuerdas del otro extremo de las vigas.

Entre Vega y Alto Real el valle es abierto y llano, de unos $150 \mathrm{~m}$, lo que provoca un cauce ancho pero muy poco profundo, como lo es actualmente. Quizá por ello el control del río frente a Vega no debió presentarle muchas dificultades a Escipión, aunque ignoramos con qué sistema, pues nada dice Apiano al respecto.

En cuanto a Molino, la topografía del terreno es diferente a la de Vega: el valle es algo más estrecho pero fácilmente inundable en momentos de crecida, como nos relata Schulten (1927: 87; 1945: 33) que ocurría en su época, y como sucede en la actualidad cuando se producen avenidas. Sin embargo, el cauce del río junto a Molino es más profundo que en Vega, por lo que su control debió presentar mayores dificultades.

Por tanto, los problemas de permeabilidad de la circunvalación en el río debieron surgir aguas abajo de Numancia. O al menos así parece indicarlo Apiano, pues Escipión coloca el cierre del Duero más abajo de la línea de vallum, aprovechando el lugar más idóneo para ello, allí donde el río queda constreñido entre las laderas de Cañal y Dehesilla.

Relata Apiano que el río Duero corría al pie de las murallas, queremos entender que de Numancia, ya que a continuación refiere lo útil que era a los numantinos y cómo transitaban por él en pequeños barcos de remo y vela. Aunque en algunas traducciones se interpreta que este muro corresponde al muro de la circunvalación romana (Gómez Espelosín, 1993: 117; Sancho Royo, 1980: 181), Schulten hace notar que, para el clasicista Schweighäuser, con el término $\tau \tilde{\varphi} \pi \varepsilon \rho \iota \varepsilon \iota \chi i ́ \sigma \mu \alpha \tau \iota$ Apiano se está refiriendo a la muralla de Numancia; aunque con dudas, Schulten (1905: 69, nota 2) parece aceptar que el término está indicando el muro de circunvalación, pero después, en las Fontes Hispaniae Antiquae, interpreta que son las murallas de Numancia: «Además, el río Duero, que pasaba al pie mismo de las murallas, era muy útil a los numantinos...» (Schulten, 1937: 297), con lo que está indicando que el río era de utilidad a los numantinos precisamente porque pasaba muy cerca de las murallas de la ciudad.

Esta utilidad del río para los numantinos era porque se servían de él para romper el cerco, tanto aguas arriba como aguas abajo de Numancia en opinión de Schulten, lo que obligó a Escipión a cerrarlo en los dos puntos donde confluían río y circunvalación mediante los castillos ribereños de Vega y Molino: «Apiano no habla de dos obstáculos, pero de su crónica se deduce claramente que el río estaba cortado tanto aguas arriba como aguas abajo de la ciudad» (Schulten, 1905: 69).

Pero la crónica de Apiano admite otras interpretaciones.

En el relato, Apiano parece estar contraponiendo el uso de los remos al uso de las velas: menciona que los remos eran empleados a favor de la corriente; por tanto, y como ya se percatara Schulten (1905: 69), la narración parece requerir de un concepto opuesto para el uso de la vela, que falta en el texto, pero se sobreentiende, como es navegar corriente arriba. Sin embargo, la diferencia con la interpretación de Schulten radica en que Schulten hacía navegar los botes de vela corriente arriba o los botes de remos corriente abajo, tanto para entrar como para salir de la ciudad.

Pero esta interpretación es cuestionable, ya que, como hemos dicho anteriormente, el Duero en la zona de Vega es ancho pero muy poco profundo, incluso crecido, y por tanto fácilmente controlable. Los romanos no habrían dejado pasar barcos por aquí. 
Teniendo esto en cuenta, se puede interpretar que los víveres y refuerzos que les llegaban a los numantinos remontaban el río con ayuda de las velas, cuando el viento era muy fuerte, hasta Numancia; tiene fundamento en que los vientos dominantes en el Alto Duero en los meses finales del otoño proceden del oeste y suroeste (Santonja, 1970: 46-50; VV.AA., 1988: 60). Habría sido difícil remontar el Duero con velas a partir de Numancia, pues aquí el río toma dirección oeste, y se navegaría contra el viento y contra la corriente. Por el contrario, la salida de los numantinos se producía en botes de remos a favor de la corriente, desde Numancia.

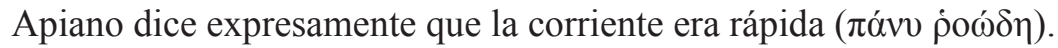

Esta utilización del río para la navegación habría requerido, en opinión de Capalvo (1999: 190), un embarcadero para el resguardo de los botes, con un acceso desde la ciudad, matizando, por otro lado, que se trataría de un tráfico fluvial muy localizado, y quizá puntual, y nunca de una navegación regular (Sillières, 2007: 391-392)

En consecuencia, parece que todas estas acciones que relata Apiano en $I b .91$ se produjeron aguas abajo de Numancia, es decir, en la zona de Molino.

La fuerte corriente del río no era impedimento para colocar las vigas con los hierros, pero sí la anchura, por lo que se debía encontrar un punto, no lejos del trazado de la circunvalación, donde las orillas del río estuvieran más próximas. Este lugar lo encontró unos $400 \mathrm{~m}$ más abajo de Molino, donde el río queda constreñido entre los cerros de Cañal y Dehesilla. Allí el valle se estrecha entre $70 / 80 \mathrm{~m}$. Y aunque la actual configuración topográfica del río no refleja necesariamente cómo pudo ser hace más de 2.000 años (cauce menos encajado, márgenes menos excavadas, etc.), el aspecto general del valle y de las laderas no han debido sufrir modificaciones relevantes.

\section{DESARROLLO DIACRÓNICO DE LA CAMPAÑA DE ESCIPIÓN EN EL RELATO DE APIANO Y EL CIERRE DEL DUERO}

En el relato de Apiano encontramos algunas pinceladas de cronología relativa que nos pueden servir para acercarnos al desarrollo diacrónico de la campaña de Escipión y, posteriormente, establecer el momento en que se efectuaron las obras de la circunvalación de Numancia y el cierre del río.

En $I b .87$ Escipión, tras entrenar el ejército, se traslada «cerca de los numantinos» ( $\dot{\alpha} \gamma \chi 0 \bar{v})$. Schulten (1945: 138-140; 1937: 70) interpretó que ese acercamiento era a las llanuras del Ebro central, en la región de Turiaso y Augustobriga hacia finales de mayo o principios de junio. Sin embargo, también se ha sugerido que este acercamiento debe entenderse mucho más próximo a Numancia, y que podría corresponder a la ocupación del campamento IV de la Gran Atalaya de Renieblas, un campamento de verano (Fabricius, 1911: 378-382). Estando aquí, recogía provisiones en los alrededores y «segaba el trigo todavía verde»; en esta región el trigo ya granado está verde hacia mediados/finales de junio.

A continuación (Ib. 88) se produce la expedición de castigo a tierras vacceas: Pallantia, el regreso por Cauca, y las marchas nocturnas para evitar la sed, acontecimientos que debieron producirse en los meses de julio y agosto, que es cuando se registran las máximas temperaturas en el interior peninsular (hasta $40^{\circ}$ ).

«Y [Escipión] avanzó hacia los numantinos para pasar el invierno» (Ib. 89). La llegada a tierras numantinas pudo tener lugar a finales de agosto o primeros de septiembre. ¿Dónde instaló su campamento? Schulten cree que Escipión se situó directamente ante Numancia en los campamentos de Castillejo y Peña Redonda. Pero no debió ser así, ya que Apiano dice que, no

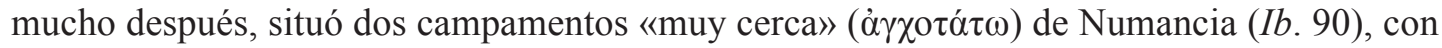


lo que está indicando que antes de situarse «muy cerca» sólo estaba «cerca», y desde esa posición se dedicaba a saquear y devastar los alrededores. Se ha sugerido que en la segunda llegada a tierras numantinas, Escipión ocupó de nuevo la Gran Atalaya de Renieblas, pero que ahora construyó un campamento de invierno, el campamento V (Fabricius, 1911: 378-382; Sanmartí, 1992: 418-420), aunque esta cronología está en entredicho (Luik, 1997; 2002; Salvatore, 1996; Gómez-Pantoja y Morales, 2002; Dobson, 2008; Dobson y Morales, 2008). También se han aportado otras alternativas fundadas en los restos constructivos (Dobson, 2008: 188 y ss. y 387).

Desde su campamento en la Gran Atalaya de Renieblas, Escipión debió dedicar todo el mes de septiembre no sólo a saquear y devastar los alrededores, sino también a tantear a los numantinos. Quizá tras estas escaramuzas se planteó asediar la ciudad, teniendo tiempo suficiente de explorar la topografía de los alrededores de Numancia y proyectar y ejecutar las obras del cerco antes de que comenzaran los rigores del invierno meseteño.

El dispositivo táctico del asedio de Numancia, tal como lo describe Apiano, se desarrolló en varios tiempos:

1) Instalación de sus tropas «cerca» de Numancia.

2) Construcción de dos campamentos «muy cerca» de Numancia.

3) Construcción de siete fuertes y comienzo del asedio.

4) Excavación de un foso y levantamiento de una empalizada rodeando la ciudad y uniendo los campamentos y fuertes.

5) Excavación de otro foso no muy lejos por encima del anterior, con empalizada sobre él, y construcción de un muro de ocho pies de grueso y diez de alto sin contar las almenas, con torres cada cien pies.

Supone Schulten (1927: 36) que en esta empresa (fuertes y vallum) pudo emplear Escipión entre cinco y veinte días que posteriormente concreta en diez días (1945: 160), por lo que la circunvalación pudo quedar terminada a fines de octubre.

6) Construcción de dos fortines, uno en cada orilla, en lugar de un puente, para cortar el río mediante grandes vigas con hierros clavados.

Con posterioridad a la conclusión de los trabajos de circunvalación, debieron producirse algunas acciones numantinas rompiendo el asedio por el río para que Escipión decidiera cerrarlo, inicialmente con un puente, y después, viendo la imposibilidad de ésta opción, con los mecanismos descritos por Apiano. Por tanto, las obras del cierre del Duero debieron estar concluidas hacia finales del mes de noviembre del año 133 a.C.

Apiano no concreta si la anchura del río era la habitual o si era ancho por bajar crecido. No obstante, es en esta época del año cuando se producen las máximas precipitaciones otoñales, provocando crecidas que desbordan el cauce normal del río e inundan extensas zonas del valle, especialmente las llanuras fluviales que se abren frente a Vega y Molino, y cuyo espectáculo desanimó a Escipión de construir el puente. Pero independientemente de que fueran aguas normales o de avenida, podemos preguntarnos cómo era de ancho el río para ser inviable tender un puente.

La construcción de los diques se hizo siendo el río «ancho», por lo que son los propios diques, o más exactamente la base de los diques, la que nos indique la magnitud de su anchura. En este sentido, el dique de Dehesilla, más bajo de base, no necesitó de construcciones complementarias (fig. 10). Por el contrario, el dique de Rasa, más elevado, requirió de la construcción de un largo suplemento de piedra para acercar su base al río. Por tanto, la distancia entre las bases de uno y otro dique, unos $80 \mathrm{~m}$, es la anchura aproximada que alcanzaba el río en ese 


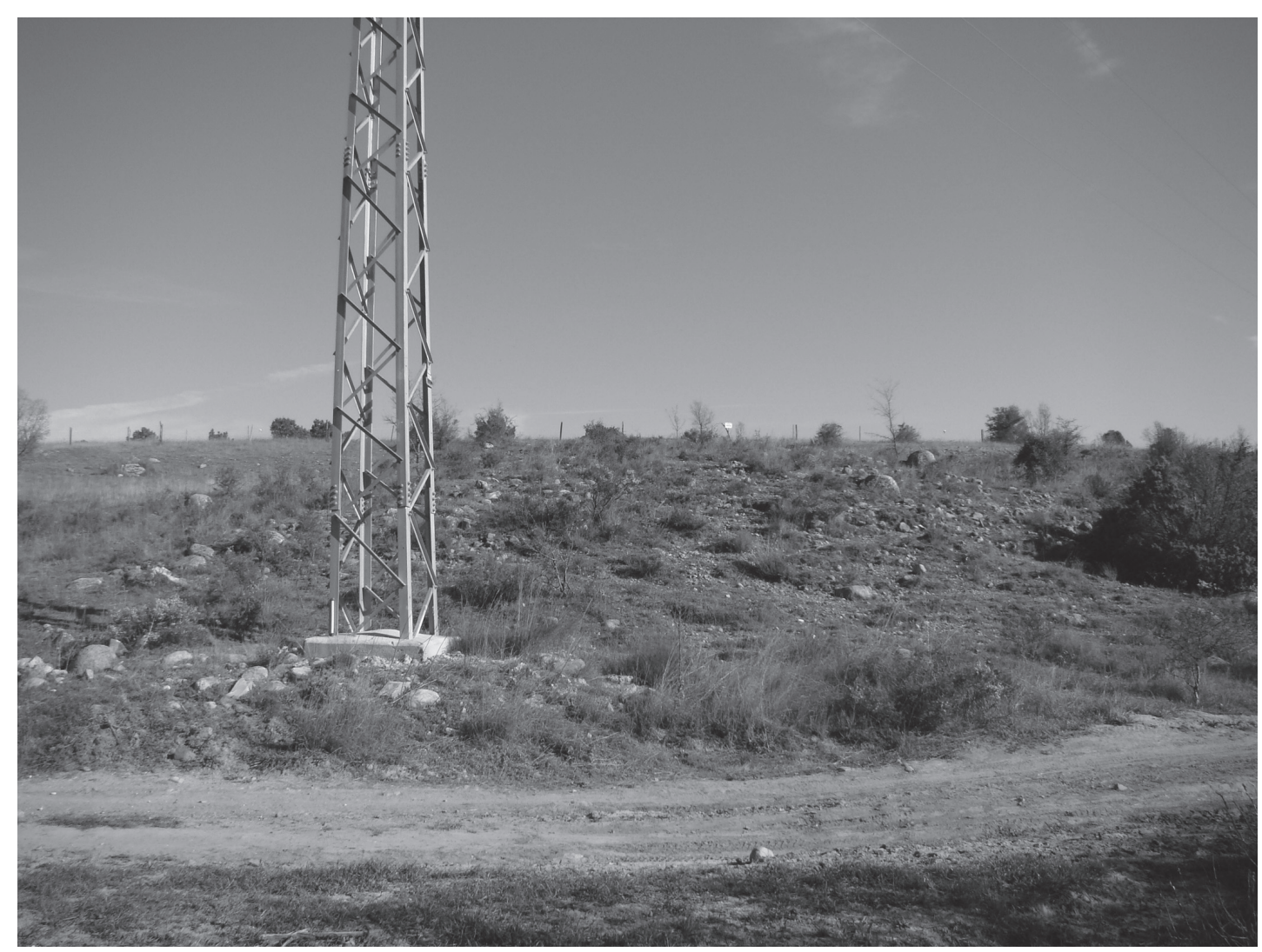

Figura 10. Estado actual de los restos del dique de Dehesilla; en su base, un poste eléctrico de reciente instalación.

momento, y que quedó cristalizada en los diques. Y considerando que los diques llegaron hasta las aguas (normales o crecidas) del río, la altura que alcanzaron éstas ${ }^{1}$ sobre un teórico fondo antiguo fue de unos 3,25 m, y de unos 3,75 m sobre el fondo actual. Con estos parámetros, y conociendo el perfil del valle, que, como ya hemos dicho anteriormente, no ha debido sufrir modificaciones relevantes, podemos saber que el volumen de la avenida fue de entre 150 y 190 $\mathrm{m}^{3} / \mathrm{s}$ (caudal medio anual $\left.12,9 \mathrm{~m}^{3} / \mathrm{s}\right)^{2}$, en cualquier caso un aforo de agua considerable que,

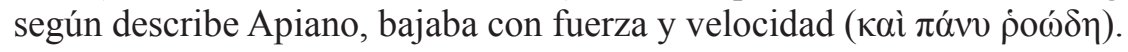

1 Desconocemos la configuración antigua del cauce del río, quizá menos ancho y menos profundo; es posible que hace veintidós siglos el cauce tuviera menos anchura que hoy. En este sector, las orillas del Duero están constituidas por suelos de materiales cohesivos, con alto contenido en arcillas, resistentes a la erosión superficial, pero susceptibles de rotura por descalzamiento cuando se producen episodios de descenso del nivel de las aguas. Esta inestabilidad lateral del cauce produce un retraimiento progresivo de las orillas dando lugar a un cauce más ancho. No obstante, también hay que tener en cuenta que la morfología del río en este tramo, bastante rectilíneo, produce una menor erosión de los taludes.

En lo que respecta a la profundidad, el cauce ha debido sufrir una escasa erosión a lo largo de los siglos, según nos informa el Servicio de Aforos de la Confederación Hidrográfica del Duero (comunicación personal), ya que el lecho en esta zona numantina está constituido fundamentalmente por materiales cuarcíticos de granulometría gruesa, entre 1000 y $250 \mathrm{~mm}$ (cantos rodados), o media, entre 250 y $64 \mathrm{~mm}$ (guijarros), de gran resistencia a la erosión del fondo, evitando el arrastre de los sedimentos más finos y, por tanto, la excavación y encajonamiento del cauce.

2 Todos los valores proceden del caudalímetro de la Confederación Hidrográfica del Duero en Garray, situado en la orilla derecha del río, unos $80 \mathrm{~m}$ más abajo de los diques. 
Esta descripción no difiere mucho de las que nos ofrece Schulten a principios del siglo XX:

En la actualidad, el río sólo llega a los 30-40 metros de ancho en verano, pero en invierno sube hasta 3 metros, (de 1014 a 1017). Al principio del sitio, en el invierno del 134 al 133 a.C., el valle seguramente se vería, como de hecho aún sucede hoy frecuentemente en invierno, cubierto de estrepitosas crecidas del Duero, de manera que el río llegaría hasta los 80 metros de ancho, 40 metros más de lo habitual (Schulten, 1927: 87).

Y en términos similares habla de las crecidas del río Merdancho:

Yo mismo soy testigo de cómo el arroyo Merdancho, junto a Numancia, que atravesábamos de un salto, a causa de una lluvia en la montaña se llenó de agua en una anchura de 100 metros en sólo el término de una hora (1945: 33).

Esta característica de la corriente (impetuosa, violenta, rápida, según las diferentes traducciones) tiene su explicación en el desnivel del terreno. Así, en el tramo inicial del Duero, entre sus Fuentes y la ciudad de Soria, de unos $73 \mathrm{~km}$, la pendiente media es de 14,8 m/km. Sin embargo, en los 32,6 km anteriores a los diques, es decir, entre la presa de La Cuerda del Pozo (1069 m s.n.m.), donde el río adquiere ya un perfil más plano, y el fuerte de Molino (1007 m s.n.m.), el desnivel medio es de tan sólo $1,90 \mathrm{~m} / \mathrm{km}$, que sin ser una pendiente fuerte, casi duplica el desnivel medio $(1 \mathrm{~m} / \mathrm{km})$ que hay en los siguientes $500 \mathrm{~km}$ que separan la ciudad de Soria y la frontera portuguesa.

Una avenida de agua como la citada, de entre unos 150 y $190 \mathrm{~m} 3 / \mathrm{s}$, desplazándose por un cauce con una sección de entre unos $160 \mathrm{~m}^{2}$ —antigua - y $172 \mathrm{~m}^{2}$ —actual—, se movería a una velocidad de entre 0,9 y $1,1 \mathrm{~m} / \mathrm{s}$, lo que sin duda es ya una corriente muy rápida, tal y como nos relata Apiano que sucedía con el Duero.

\section{BIBLIOGRAFÍA}

Alarcos, E. (1994): Gramática de la Lengua Española. Madrid, Espasa Calpe.

Alfageme, I. R. (1988): Nueva gramática griega. Madrid, Coloquio.

Archilla Aldeanueva, R. (1987): Características climáticas y agrícolas de la provincia de Soria. Soria, Publicaciones de la Excma. Diputación Provincial.

Astin, A. (1967): Scipio Aemilianus. Oxford, Clarendon.

Berenguer Amenós, J. (2003): Gramática griega. Bosch, Barcelona.

Capalvo Liesa, A. (1996): Celtiberia: Un estudio de fuentes literarias antiguas. Insttitución Fernando el Católico. Zaragoza.

Diaz Tejera, A. (1972): Polibio: Historias. CSIC, Madrid-Barcelona.

Diaz Tejera, A. (1988): «Apiano», J. A. López Férez (ed.), Historia de la literatura griega. Madrid, Cátedra: 1066-1073.

Dobson, M. (2008): The Army of The Roman Republic. The second century BC, Polybius and the camps at Numantia, Spain. Oxford, Oxbow Books.

Dobson, M. y Morales, F. (2008): «Monedas inéditas de los campamentos romanos republicanos del cerco de Escipión y de la Gran Atalaya de Renieblas, y algunas consideraciones cronológicas sobre el campamento V de Renieblas». Archivo Español de Arqueología, 81: 213-228.

FABricius, E. (1911): «Über die Ausgrabungen in Numantia». Archäologischer Anzeiger.

Gómez Espelosín, F. J. (1993): Apiano: sobre Iberia y Aníbal. Madrid, Alianza.

Gómez-Pantoja, J. y Morales, F. (2002): «Sertorio en Numancia: una nota sobre los campamentos de la Gran Atalaya». Gladius, Anejos 5: 303-310. 
Goukowsky, P. (1997): Appien. Histoire Romaine. Paris, Les Belles Lettres.

Haeberlin, E. J. (1929): «Die Münzen aus der Stadt Numantia, den Lagern des Scipio und den Lagern bei Renieblas», A. Schulten: Numantia IV. Die Lager bei Renieblas. München, Bruckmann: 235-283.

Hildebrant, H. J. (1979): «Die Römerlager von Numantia. Datierung anhand der Münzfunde». Madrider Mitteilungen, 20: 238-271.

JimENo, A. (2002): «Numancia: campamentos romanos y cerco de Escipión». Archivo Español de Arqueología, 75: 159-176.

Jimeno, A.; Revilla, M. ${ }^{a}$ L.; Torre, J. I. de la Berzosa, R. y Martínez, J. P. (2002): Numancia. Garray. Soria. Guía Arqueológica. Soria.

LuiK, M. (1997): Fibels von Typ Alesia aus den römischen Lagern um Numantia. Archäologisches Korrespondenzblattz, 27.

LuIK, M. (2002): Die Funde aus den römischen Lagern um Numantia im Römisch-Germanischen Zentralmuseum. Mainz, Römisch-Germanisches Zentralmuseum.

Morales Hernández, F. (1995): Carta Arqueológica de Soria. La Altiplanicie Soriana. Soria, Publicaciones de la Excma. Diputación Provincial.

Morales Hernández, F. (2004): «Los campamentos y fuertes romanos del asedio de Numancia», C. Pérez-González y E. Illarregui (coords.) 2004: Actas de Arqueología Militar Romana en Europa (Segovia 2001). Salamanca, Universidad Internacional SEK-Junta de Castilla y León: 251-258.

Morales Hernández, F. (2006): «Circunvallatio of Numantia. Forts and siege Works», A. Morillo y J. Aurrecoechea (eds.), The Roman Army in Hispania. An Archaeological Guide. León, Universidad de León: 249-262. Y también en A. Morillo (ed.), El ejército romano en Hispania. Guía Arqueológica. León: 263-276.

Morales Hernández, F. (e.p.): «El trazado de la circunvalación de Numancia. Pasado y presente de la investigación», Actas del XX Congreso Internacional de la Frontera Romana (León 2006).

Morales Hernández, F. y Dobson, M. (2005): «Why 'La Rasa' was not a camp of the Scipionic siege of Numantia». Madrider Mitteilungen, 46: 104-111.

Romagosa, J. (1972): «Las monedas de los campamentos numantinos». Acta Numismática, II: 87-96.

SaAvedra, E. (1879): Descripción de la vía romana entre Uxama y Augustobriga. Madrid.

SAlVATORE, J. P. (1996): Roman Republican Castrametation. A reappraisal of historical and archaelogical sources. BAR International Series 630. Oxford.

SAncho Royo, A. (1973): «En torno al Bellum Numantinum de Apiano». Habis, 4: 23-40.

Sancho Royo, A. (1980): (trad.) Apiano. Historia Romana. Madrid, Alianza.

SANMARTí-Grego, E. (1985): «Sobre un nuevo tipo de ánfora de época republicana, de origen presumiblemente hispánico», M. Picazo y E. Sanmartí (eds.), Ceràmiques gregues i helenístiques a la Península Ibèrica:: Taula Rodona amb motiu del 75è aniversari de les excavacions d'Empuries, Empúries, 18-20 març 1983. Monografies Emporitanes VII, Barcelona, Institut de Prehistòria i Arqueologia: $133-141$.

Sanmartí-Grego, E. (1992): «Nouvelles données sur la chronologie du camp de Renieblas V á Numance (Soria, Castilla-León, Espagne)». Documents d'Archéologie Méridionale, 15: 417-430.

Sanmartí-Grego, E. y Principal, J. (1997): «Las cerámicas de importación, itálicas e ibéricas, procedentes de los campamentos numantinos». Revista d'Arqueologia de Ponent, 7: 35-75.

SAntonja Peris, L. y otros (1970): Desarrollo de la agricultura y ganadería sorianas, I. Confederación Española de Cajas de Ahorros. Madrid.

SChulten, A. (1905): Numantia. Eine topographisch-historische Untersuchung. Berlin.

Schulten, A. (1908): «Les camps de Scipion à Numance. Premier rapport. (Fouilles de 1906)». Bulletin Hispanique, X: 128-156.

Schulten, A. (1909): «Les camps de Scipion à Numance. Deuxième rapport. (Fouilles de 1907)». Bulletin Hispanique, XI: 1-24.

Schulten, A. (1927): Numantia. Die Ergebnisse der Ausgrabungen 1905-1912. III, Die Lager des Scipio. München, Bruckmann.

Schulten, A. (1937): Fontes Hispaniae Antiquae, 4. Las guerras de 154-72 a.C. Barcelona, Bosch.

Schulten, A. (1945): Historia de Numancia. Barcelona, Barna.

Sillières, P. (2007): «Les communications routières et fluviales en Hispanie: l'exemple de l'axe ÉbreDouro», M. Navarro Caballero, J. J. Palao Vicente y M. ${ }^{a}$ A. Magallón Botalla (coords.), Villes et 
territoires dans le bassin du Douro à l'époque romaine (Bordeaux, septembre 2004). Bordeaux, Ausonius.

Taracena Aguirre, B. (1941): Carta Arqueológica de España: Soria. Madrid.

VV.AA. (1988): Análisis del Medio Físico de Soria. Delimitación de unidades y estructura territorial. Valladolid, Junta de Castilla y León.

Recibido: 17/05/2008

Aceptado: 09/06/2008 